\title{
Effect of Workplace Comfort on Operator Performance
}

\section{Pavel Kábele *, Milan Edl}

University of West Bohemia, 22 Univerzitní St.,32600 Pilsen, Czech Republic

\begin{abstract}
Working conditions largely affect the mental state of Operators and their physical state, which in turn affects the overall performance of operators. However, many businesses are not sufficiently informed or underestimated. The result is dissatisfied employees, poor performance and quality of work. This work is devoted to theoretical knowledge in the given area. There are presented theoretical bases of labour productivity, on the basis of which is proposed methodology of workplace comfort assessment to Operator performance. The study "The impact of workplace comfort on the performance of Operators" falls within the fields of industrial engineering and ergonomics. This problem is very topical because the ergonomic arrangement of workplaces is now solved as secondary, especially the modularity of the workplace. The introductory part describes the knowledge gained from the scientific literature concerning all effects on the performance of Operators, performance curves and process productivity. The most common optimization criterion is the total cost of the product produced, mostly in the form of human labour. Part of the thesis is also a summary of theoretical knowledge, which are linked to the objectives and partial goals of the dissertation. Everything ends with the expected procedure for meeting these goals and a list of expected benefits of the resulting study.
\end{abstract}

Keywords: Productivity; Ergonomic; Workplace; Performance; Evaluation; Operator

\section{Introduction}

Nowadays, the market environment is characterized by words such as turbulent, global, customer-oriented, etc. At present, it is becoming increasingly difficult to achieve success in such a product and service market or to maintain or gain a competitive edge. In all areas of industrial production, manufacturers are forced by their customers to deliver new products in an ever-shorter period of time, at the highest quality and at the lowest possible price. Innovations in the field of information and communication technologies push product development constantly forward, often at the cost of unsuitable ergonomic design of the workplace. Then there are situations where the physical and psychological possibilities of a person are overloaded, which can lead to damage to his / her health and loss of performance. Many companies optimize their workplaces today and daily. The most common optimization criterion is the total cost of the product produced, mostly in the form of human labour. However, optimization activities are often not systematic and often managed very spontaneously. [1-10]

\section{Literature Review}

Productivity is the value of how much available resources are used to create product values. Its most general expression is the ratio between the output of the process and the input of the necessary resources into the process. Thus, the general formula for calculating productivity is as follows:

Productivity = Output $/$ Input 
The productivity level is described as a value that is determined by the ratio of the volume of production to the volume of inputs used over a period: the more useful goods are produced using less resources, the more productivity increases. Productivity is in the broadest sense divided into different levels to which the individual inputs and outputs are related. These levels represent national productivity, team or individual productivity. Knowledge of the issues and factors affecting productivity, whether at the level of companies, departments or organizational units, to improve productivity is dealt with by an industrial engineer or manager. Higher productivity can then be seen as more output than the amount of inputs or achieving more goals with the same resources. [1] [5] [13]

In seeking ways to deliver the necessary productivity gains, a business must concentrate heavily on the growth and improvement of the four basic factors affecting productivity. These are factors - utilization, performance, quality and production methods. When looking for resources that will enable productivity growth in a business, it is advisable to address in particular:

- Creating a climate for high productivity

- Use of techniques and methods to increase productivity

- Improving the Operator's relationship to work

- Eliminate waste in individual processes

- Strengthening the human-machine bond

- Improve development and innovation speed [6-11]

\subsection{Operator evaluation}

Bedrnová and Nový [8] argue that in each undertaking the evaluation of operators is a very important activity. The aim of this evaluation is to create a picture of the results and perspectives of the assessed Operator, to point out his / her performance and to point out mistakes. The assessment of the operator and his / her work also plays a particularly important role in managing remuneration and ensuring that cash remuneration is fair.

Operator evaluation can be seen as a tool for achieving business goals, supporting employee initiative, and strengthening the authority of a manager whose competence is just assessing and evaluating work performance.

There are many methods of employee evaluation, but personal practice prefers those that are most easily understood and manageable. In 1992, Werther and Davis divided employee evaluation methods into two groups, either by assessing the work already done, i.e. past-oriented, or by identifying a Operator's development potential, i.e. future-oriented. [11]

Work performance management is based on the process of improving work performance and developing skills [4]. Work performance management involves two basic tasks - work performance planning and improvement and work performance evaluation. The proceedings concern mainly individual performance and development, but can also be applied in the management of departments. Good performance management is, according to Koubek [9]: "linked to creating and sharing a vision of the purpose and goals of the organization", which focuses on:

- Improving work performance and employee development,

- Meeting the needs of all stakeholders

\section{- Communicate and engage people in discussion}

\subsection{Effects on performance}

Depending on the ever-increasing emphasis on ergonomics, the theme of comfort-able workplace appears, which should ensure that each Operator can optimally adjust the workplace according to their physical proportions.

The design of a universal workplace is based on the anthropometric dimensions of either the 95th or 99th percentile of the population of predicted users. 99th percentile values are used for emergency escape routes or for selected work systems system [EN 547-1: 1998 (83,350)]. If we want to work on improving ergonomics, purchasing workplaces with height adjustment is a good idea, but it must not be left alone. Re-placement of workplaces should be preceded by a thorough assessment of the risks associated with its use, which will help you clarify your needs and then choose the most appropriate solution for employees.

\section{Research Methodology}

The main parameter influencing performance is the adjustability of the workplace. That is why literature dealing with the change of workplace and the influence of monotonicity on the Operator was mapped. The aim was to identify possible methods of the impact of workplace change on the performance of Operators. Based on the studied literature and the above-mentioned searches, which provide a comprehensive view of the issue of employee performance and changes in the 
workplace, the phrases have been defined.

- The working environment affects the Operator's performance.

- Workplace rationalization is a change in workplace parameters that will increase workplace productivity.

- We understand the change in workspace layout as a rationalization of the workplace.

- Rationalization of the workplace leading to ergonomic arrangement and equipment of the working place contributes to the feeling of working comfort.

- Changing the workspace layout changes the time required to complete the process. (proven by MTM calculation and represents the delta change between original and innovated state)

- A standardized workplace (standardized height of handling areas) is comfortable only for a certain percentile of Operators.

In practice, there may be three different types of workplace conditions. Phrases states are divided into the original state of the workplace, the state where the workplace is universal and the state where the workplace is adjustable. The division is shown in the figure 1.

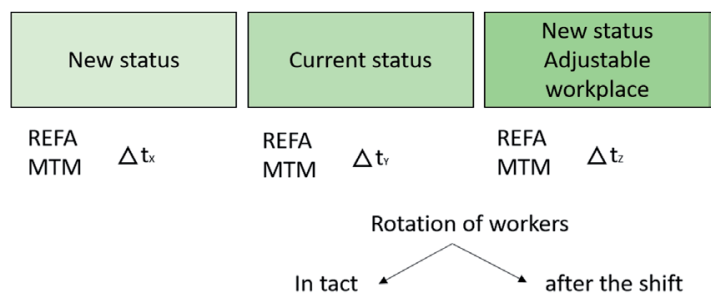

Figure 1: Three states of the workplace.

The original state of the workplace can be understood as a workplace that is not subjected to industrial engineering methods. Such a workplace does not satisfy either ergonomic or rationalization aspects. If we performed an MTM or MOST analysis at this site and compared it with the REFA methodology, the difference tx would be high.

The new - universal state of the workplace shows the situation when the workplace is adjusted after the intervention of rationalization and ergonomic methods of normative day and anthropometric data on the average (universal) person. Height and distances are defined for the unisex person (height $172.7 \mathrm{~cm}$ ).

Comfortable state of the workplace is a situation when the Operator at this workplace sets the workplace according to his / her physical proportions. Such a workplace is adjustable and at the same time works with rationalization measures. This type of workplace is the best way to prevent

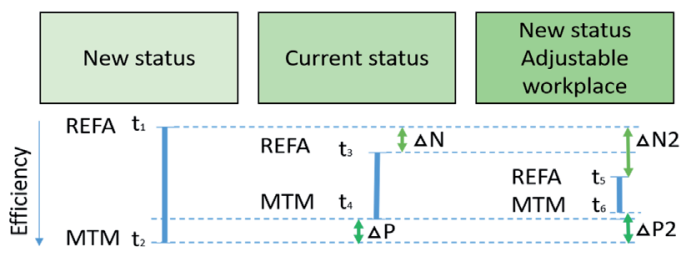

Figure 2. Time analyses at workplaces.

occupational diseases while making this work-place lean.

Figure 2 shows the breakdown of analyses that would be performed in the workplace. In the first case, i.e. in its original state, the greatest difference between $\mathrm{t} 1$ and $\mathrm{t} 2$ can be seen. In the universal state we then work with the idea that $t 2>t 4$, i.e. there were rationalization and ergonomic improvements. For the average person, the difference in times $t 3$ and $t 4$ will be less than the difference tx. For the third situation, for the average person, the productivity of his work should not change, for other Operators there should be an improvement. This improvement represents the difference in times $t 3$ and $t 5$.

The time difference, which is the $\Delta \mathrm{P}$, is caused by the workplace setting. This effect can be seen in the example where the MTM for time t2 is greater than $100 \%$. The difference between this value and 100\% is due to a poorly set workplace. For MTM t4, the value should be $100 \%$ because optimum workplace improvement is achieved. Time $\Delta N$ is caused both by the influence of the workplace, specifically as it is organized, and by the psychological aspect of the Operator and his anthropometric data. In the case of a comfortable workplace, the assumption of the work of the average person is $\Delta N=\Delta N 2$. However, every other Operator will have a deviation and status $N \neq \Delta N 2$. Both differences $\Delta N$ and $\Delta N 2$ are caused by the psychological aspect and the workplace.

\section{Results and Discussion}

Figure 3 illustrates how theory defines Operatortype dependence on performance. The graph shows that if we consider the average Operator at the universal workplace, his performance will be maximum, i.e. $100 \%$. However, if there was another Operator in the workplace, then the value should theoretically decline. For example, if we wanted to know the performance of an Operator who measures $155 \mathrm{~cm}$, the answer should be $100 \%$ hy. Conversely, it can be argued which Operator achieves only $80 \%$ of performance in a particular workplace. The curve 
shown in the figure contains only a theoretical basis but has not actually been verified by anyone.

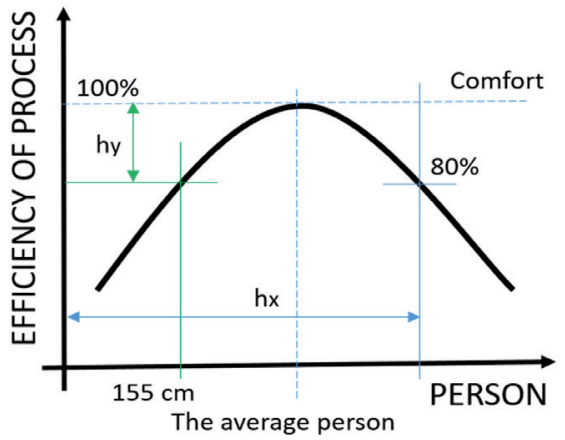

Figure 3. Dependence of performance on the type of Operator.

It follows from these starting points that the working environment affects the Operator. If the workplace is rationalized, performance and productivity will increase. The question arises, however, of the relationship between the original productivity of the Operator and the new productivity, where an adjustable comfort workplace for each Operator will be considered. The aim of the next work is therefore to establish a real dependence between the comfort of the workplace and the productivity of the Operator who works at that workplace.

The result of the theoretical analysis was to establish the objective of practical verification of the scientific study. As a secondary objective, it was necessary to establish a procedure for verifying the established hypotheses.

\section{Conclusion}

Working conditions largely affect the mental condition of Operators and their physical condition, which in turn affects the overall performance of Operators. However, many businesses are not sufficiently aware or underestimated. The result is dissatisfied employees, poor performance and quality of work. This paper is devoted to theoretical knowledge in this area. There are presented theoretical bases of labour productivity, on the basis of which will be proposed methodology of workplace comfort assessment on Operator performance.

Establishing a methodology for successful achievement of the main objective:

- Selection of appropriate methodology for measuring employee performance

- Determination of general model for measuring Operator performance-labour productivity

- Choosing a work process where it will be possible to observe the effects of workplace comfort on Operator performance

- Selection of suitable approaches for the rationalization of the workplace in relation to the anthropometric parameters of the Operator (setting of the workplace according to the anthropometry of the Operator)

- Summarization of factors entering the algorithm

- Validation of algorithm of influence of workplace comfort on Operator performance

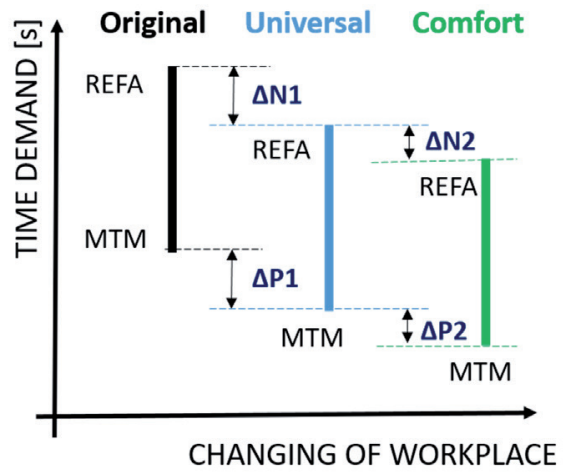

Figure 4 Dependence of performance on the type of Operator.

In conclusion, we assume that the MTM gives 100\% table performance and REFA measures the real Operator, so if the $\triangle P 1$ has the same value as the $\Delta N 1$, the work-place adjustment will have no effect on working comfort. If there is a situation where the $\Delta P 1$ value is lower than the $\Delta N 1$, then it can be argued that adjusting the site affects the Operator's comfort.

\section{Acknowledgement}

This paper was supported by the Internal Grant Agency of the University of West Bohemia, project No. SGS-2012-063 "Integrated design of manufacturing system as metaproduct with a multidisciplinary approach and with using elements of virtual reality." This paper was created with the subsidy of the project CZ.1.05/2.1.00/03.0093 "RTI - Regional Technological Institute" carried out with the support of Ministry of Education, Youth and Sports.

\section{References and Notes}

1. CONNER, G., Lean Manufacturing for the Small Shop. Dearborn, Mich.: Society of Manufacturing Engineers, ISBN 0872635201. (2001).

2. PORTER, M. E., Competitive Strategy: Methods for Analysis of Industry and Competitors. Prague: Victoria Publishing, [in Czech], 
ISBN 80-85605-11-2. (1994).

3. Wilson, L., How to implement lean manufacturing. New York: McGraw-Hill, ISBN 0071625070. (2010).

4. IMAI M. Kaizen: A method for introducing more economical and flexible production in an enterprise. 1.vyd. Brno: Computer Press, ISBN 978-80-251-1621-0. (2007).

5. MAŠÍN, I., VYTLAČIL, M., New Ways to Higher Productivity: Industrial Engineering Methods. Liberec: Institute of Industrial Engineering, [in Czech], ISBN 80-902235-6-7. (2000).

6. WAGNER, J., Performance measurement: how to measure, evaluate and use information about business performance. Prague: Grada, Prosperity of the company, [in Czech], ISBN 978-80-247-2924-4. (2009).

7. JONES, E. C., Quality management for organization using lean Six Sigma techniques. Boca Raton: CRC Press, ISBN 978-1-4398-9782-9. (2014).

8. BEDRNOVÁ, E., NOVÝ, I., Psychology and sociology of management. 3,. et al. Prague: Management Press, [in Czech], ISBN 978-80-7261169-0. (2007).

9. KOUBEK, J., Performance management. Prague: Management Press, [in Czech], ISBN 80-7261-116-X. (2004).

10. ARMSTRONG, M., Human resources management: the latest trends and practices. Prague: Grada, ISBN 80-247-1407-3.(2007).

11. WAGNEROVÁ, I. Performance evaluation and management. Prague: Grada, [in Czech], ISBN 978-80-247-2361-7. (2008)

12. DRUCKER, P. F., The most important of Drucker in one volume. 2nd edition. Translated by Pavel MEDEK. Prague: Management Press, World Management Library, [in Czech], ISBN 978-80-7261-397-7. (2016).

13. KOSTURIAK, J., GREGOR, M., et al. How to increase company productivity. Zilina: InForm., [in Slovak], ISBN 80-968583-1-9. (2002).

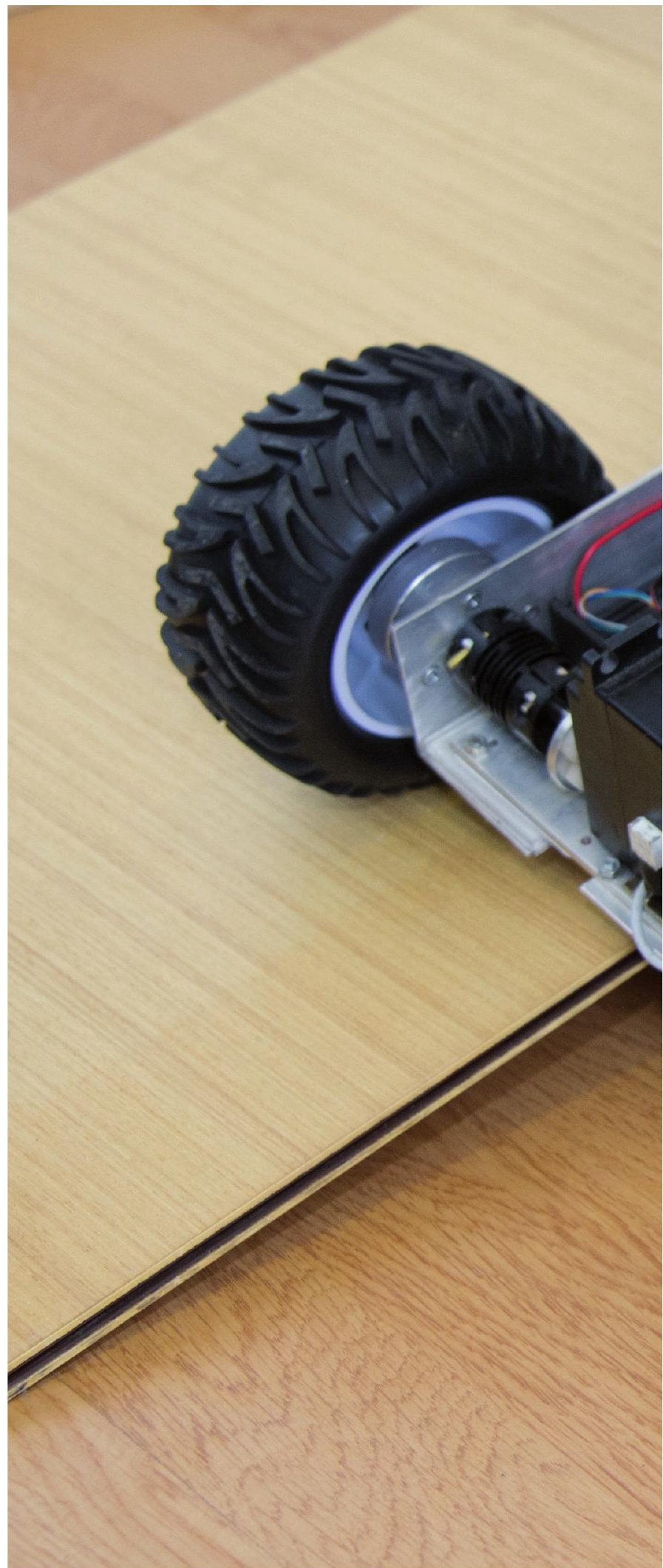

